This manuscript was published in

Singh S.P., Ma L.Q., Tack F.M.G., Verloo M.G., 2000. Trace metal leachability of land-disposed dredged sediments. Journal of Environmental Quality 29 (4), 1124-1132.

\title{
Trace Metal Leachability of Land-Disposed Dredged Sediments
}

\author{
Satya P. Singh*, Lena Q. Ma, Filip M.G. Tack and Marc G. Verloo
}

S.P. Singh* and L.Q. Ma, Soil and Water Science Dep., University of Florida, Gainesville, FL32611-0290, F.M.G. Tack and M.G. Verloo, Vakgroep Toegepaste Analytische en Fysische Chemie, Universiteit Gent, Coupure Links-653, B-9000 Gent, Belgium. Approved for publication as Florida Agricultural Experiment Station Journal Series No. R-06940* Corresponding author, spsingh@gnv.ifas.ufl.edu 
Abbreviations: LDDS, land disposed dredged sediments; GH, Geuzenhoek disposal site; MG, Meigem disposal site; LG, Lovendegem disposal site; CLT, cascade leaching test; CEC, cation exchange capacity; DOC dissolved organic carbon. 


\begin{abstract}
The potential risk of surface and ground water contamination by trace metals leached from contaminated land disposed dredged sediment is a major environmental concern. The objective of this study was to evaluate trace metal leachability, leachate quality and environmental impacts of land-disposed dredged sediments. In addition to chemical characterization and determination of potential and actual leachability, dredged sediments were also subjected to solid phase fractionation using a sequential extraction procedure. Potential leachability, defined as the maximum metal pool that may become available for leaching at a constant pH 4, decreased in the following order: $\mathrm{Zn} \sim \mathrm{Cd}>\mathrm{Mn}>\mathrm{Ni}>\mathrm{Co}>$ $\mathrm{Cu} \sim \mathrm{As}>\mathrm{Pb}>\mathrm{Cr}$. Potential metal leachability was controlled mainly by solid phase distribution of metals in sediments. The acid extractable fraction of most metals correlated well with the potentially leachable metals extracted with a solution of $\mathrm{pH} 4\left(\mathrm{r}^{2}>0.67\right)$ except for $\mathrm{Pb}$. The kinetics of metal release were determined using the cascade leaching test with water at $\mathrm{pH} 4$. Except for $\mathrm{Ni}$ and $\mathrm{Zn}$ in the first fraction, metal concentrations in all consecutive leaching fractions remained below the maximum permissible level in water for human consumption. Actual metal leachability expressed as a percentage of potential leachability varied widely among trace metals and decreased in the order: $\mathrm{As}>\mathrm{Cu}>\mathrm{Cr}>$ $\mathrm{Ni}>\mathrm{Zn}>\mathrm{Cd}>\mathrm{Co}>\mathrm{Pb}$. Our results indicate low risk of surface and ground water contamination resulting from land disposal of dredged sediments.
\end{abstract}


Large quantities of sediments are dredged each year to clean and maintain the depth of navigational waterways, harbors and estuaries worldwide. In the Flemish region of Belgium alone, an average of $3,940,000 \mathrm{~m}^{3}$ is disposed on land annually (Demoen, 1989). Land disposal of these dredged sediments may affect the surrounding environment due to the presence of harmful organic compounds and trace metals. Among other disposal alternatives such as sea dumping, landfilling and incineration, confined land disposal (upland disposal) is frequently adopted because of the increasing pressure to ban all sludge dumping at sea. Moreover, it is easy and cost effective. However, upland disposals may cause changes in their redox potential, $\mathrm{pH}$ and organic matter content of the land-disposed dredged sediments (LDDS). These physico-chemical changes may enhance the leachability and bioavailability of trace metals in sediment (Moore et al., 1988; Förstner, 1993; Gambrell, 1994), which may restrict the beneficial utilization of LDDS, particularly in landscape restoration, agriculture and construction.

The leachability and bioavailability of trace metals in soils and sediments depend on their chemical and physical associations (Bubb and Lester, 1991; Tack and Verloo, 1993; Ma and Rao, 1997). Metals in soils and sediments may form specific mineral phases, be loosely bound on exchangeable sites, co-precipitate, be adsorbed onto mineral phases, be fixed by organic matter and sulfides or be structurally bound in alumino-silicate structures (Belzile et al., 1989). The speciation of trace metals in LDDS may influence their leaching behavior. Major mineral phases in soils and sediments control their leachate chemistry and therefore control trace metal leaching via various sorption processes (Eighmy et al., 1995). A fundamental knowledge of trace metal speciation is necessary to understand, model and predict long term leaching behavior of trace 
metals in soils (Bridle et al., 1987; Lee and Touray, 1998). Sequential extraction techniques have been widely used to determine the relative amounts of trace metals associated with various operationally defined chemical fractions in soils and sediments (Tack and Verloo, 1993; Ma and Rao, 1997). This information may indicate relative association of trace metals with LDDS solid phases.

Long term leaching and migration of contaminants from improperly disposed wastes can result in contamination of both surface and ground water (Maskell and Thornton, 1998). During the assessment of environmental impacts from land disposal or utilization of dredged materials, an insight into the leaching behavior of trace metals in sediments after disposal becomes very important. The potential release of contaminants from waste materials in soils can be assessed using various single and sequential chemical extraction techniques (Quevauviller et al., 1996). However, these tests do not provide information about the intensity and kinetics of metal release under field conditions. Our current knowledge of trace metal speciation and available trace metal leachability data in LDDS using dynamic leaching tests is limited. Tack and Verloo (1991) used the German DIN-S4-38414 test to assess metal leachability in reduced dredged sediments. In the present investigation, we applied a standard leaching test procedure to estimate the potential and actual leachability of trace metals in LDDS sampled from different disposal sites. These leaching tests were originally developed by the Netherlands Energy Research Center to test the leachability of trace metals in incineration residue (Van der Sloot, 1991). The tests are regarded as standard methods for testing the leaching behavior of trace metals from industrial wastes, stabilized wastes, construction materials, soils and sediments (Van der Sloot et al., 1996). 
For the prediction of ecological impacts of trace metals, estimation of their potential leachability (i.e., the fraction of total metal content that may become leachable), is more relevant than total analysis (Van der Sloot, 1991). The potential metal leachability is based on metal extraction from solids at a constant $\mathrm{pH}$ of 4 and liquid to solid ratio (L/S) of 100. Metal extraction at high dilution (L/S ratio of 100) will minimize metal solubility limitations. Extraction at $\mathrm{pH} 4$ has been chosen to simulate the most adverse existing environmental conditions likely to be encountered in soils and sediments. Exceptionally low $\mathrm{pH}$ values occur only in sulfide-rich environments such as mine wastes.

The actual leachability of trace metals results from the soluble and very active fraction of the total metal contents. It provides detailed insight into the kinetics of metal release from the potentially mobile metal pools and assesses metal release as a function of increasing cumulative L/S ratio. It can be used to estimate trace metal release as a function of time scale under field conditions.

The objectives of this study were to: (1) characterize LDDS using a sequential extraction procedure; and (2) evaluate the potential and actual leachability of trace metals in dredged sediments. Based on the fractionation data obtained by sequential extractions, regression analysis was applied to identify independent variables and their contributions to trace metal leachability from LDDS. The studied LDDS varied in their physicochemical characteristics as well as their upland disposal times from recent ( one year) to more than 12 years. The information obtained from this leachability study could be useful in developing a hydro-geochemical model for more accurate prediction of contaminant fate and transport in the land-disposed dredged sediments. 


\section{MATERIALS AND METHODS}

\section{Sampling and Sample Preparation}

The dredged sediment samples used for this study were collected from three different confined disposal sites in Gent, Belgium. The first sample (GH) was taken from the Geuzenhoek disposal site, which received the sediments approximately one year earlier. The site was sparsely colonized by weeds. Below the surface, the sediment was still in a partially reduced state, as evidenced by its gray color. The second sample (MG) was taken from the Deinze-Meigem disposal site on the left bank of the Deviation Canal from the River Lys. The last disposal occurred three years earlier. The site was densely covered by stinging nettle (Urtica dioica L.). The third sample (LG) was taken from the Lovendegem disposal site on the Right Bank of the Deviation Canal from the River Lys. Relatively non-contaminated dredge materials were disposed here 12 years earlier. A dense spontaneously developed forest, mainly willow trees (Salix sp.), covered the area. Hydraulic filling of dredged sediments into disposal sites caused presence of texture gradients. During filling process, coarse particles tend to settle close to mouth of sediment filling pipe and fine particles tends to settle far from the filling pipe, on the opposite end. For site GH and MG, we used sediment samples from opposite side of filling pipe and for site $L G$ close to filling pipe mouth in this investigation.

At each location an area of about 0.5 hectare was selected for sampling. Dredged sediment samples from 0 to $30 \mathrm{~cm}$ depth were taken from 10 random spots in the selected area using a $1.9 \mathrm{~cm}$ diameter drill auger and were stored in plastic bags. Any surfaces litter and loose organic matter present were removed before sampling. Immediately upon arrival in the laboratory, samples were 
thoroughly mixed and air-dried for one week. The air-dried sediments were then hand-crushed in a mortar and passed through a 2-mm sieve.

\section{Sequential Extraction Procedure}

A sequential extraction procedure developed by the Standard Measurement and Testing Program of the European Community (Quevauviller et al., 1994) was applied to differentiate metal fractions in the sediments. Each extraction step and target phase are listed in the order of least to most chemically aggressive. This procedure involved three steps: (1) extraction with 0.11 mol L $\mathrm{L}^{-1}$ acetic acid; (2) extraction of residue with $0.1 \mathrm{~mol} \mathrm{~L}^{-1}$ hydroxyl amine hydrochloride acidified with $\mathrm{HNO}_{3}$ to $\mathrm{pH}$ 2; and (3) extraction of residue with $300 \mathrm{mg} \mathrm{H} \mathrm{H}_{2}$, followed by extraction with $1 \mathrm{~mol} \mathrm{~L}^{-1}$ ammonium acetate to prevent readsorption of the metals. The resulting metal fractions are referred to as acid extractable (water-soluble, exchangeable and bound to carbonate), reducible (bound to $\mathrm{Fe} / \mathrm{Mn}$ oxides) and oxidizable fraction (bound to organic matter). The residual fraction was calculated as the difference between the aqua-regia extractable metal contents and the sum of metal contents released by the sequential extractions. Because aqua-regia is not a true total extraction (Ure, 1990; Utermann et al., 1999), the residual fraction may have been slightly underestimated. Trace metals in the first three fractions are considered relatively more mobile and bioavailable than those in the residual fraction (Tack and Verloo, 1995; Ma and Rao, 1997). To check the accuracy of the used sequential extraction procedure, the reference sediment CRM 601 was also analyzed for its trace metal solid phase fractionations. 


\section{Leaching Procedures}

In this study two leaching procedures were used to estimate the leachability of trace metals in LDDS. The Potential Leachability Test was designed to assess the maximum amount of metals that could potentially become available for leaching under certain environmental conditions (Van der Sloot et al., 1996). Three grams of air-dried sediment were suspended in $300 \mathrm{~mL}$ of deionized water in an acid-rinsed $400 \mathrm{~mL}$ glass beaker and the suspension was stirred using a magnetic stirrer. Nitric acid $\left(1.0 \mathrm{~mol} \mathrm{~L}^{-1}\right)$ was added through an automatic burette (Metrohm 665 dossimat) to maintain a constant $\mathrm{pH}$ of 4 . After 4 hours, the suspensions were filtered using a paper filter (Schleicher and Schuell $589^{2}$ White Ribbon). A few drops of concentrated $\mathrm{HNO}_{3}$ were added to bring the sample $\mathrm{pH}$ to $<2$ before storing in a refrigerator.

The actual leachability of trace metals in LDDS at cumulative L/S ratio ranging from 20 to 100 was assessed by using a cascade leaching test (NEN 7341, 1994). This procedure was designed to study the kinetics of metal release from soils and sediments. The extractions were carried out in duplicate, using acid-rinsed 125-mL Pyrex glass centrifuge tubes with screw caps. An air-dried $5 \mathrm{~g}$ sediment sample was transferred to each centrifuge tube and suspended in $100 \mathrm{~mL}$ of leaching reagent (deionized water acidified to $\mathrm{pH} 4$ with ultra pure $\mathrm{HNO}_{3}$ ). The suspensions were shaken continuously for 23 hours on an end over end mechanical shaker at $30 \mathrm{rpm}$. After 15 minutes to allow settling of suspended materials, the liquid was decanted and filtered through a $0.45 \mu \mathrm{m}$ membrane filter. The membrane filter and its residue were returned to the sediment in the same bottle and 100-mL fresh leaching reagent was added. Extractions were repeated until five fractions (100 mL each) were collected. After determination of $\mathrm{pH}$, electrical conductivity and total dissolved 
organic carbon, the filtrates were acidified to below $\mathrm{pH} 2$ with a few drops of concentrated nitric acid for trace metal analysis.

\section{Chemical Analysis}

Soil $\mathrm{pH}$ was measured using a glass electrode in a 1:5 solid: liquid suspension in distilled water after equilibration for 24 hours (Cottenie et al., 1982). Electrical conductivity was measured in the saturation extract. Organic carbon was measured by the Walkley-Black method (Allison, 1965). Carbonate content was determined by back titrating an excess of $0.5 \mathrm{~mol} \mathrm{~L}^{-1} \mathrm{HCl}$ added to $1 \mathrm{~g}$ of sediment sample with $0.5 \mathrm{~mol} \mathrm{~L}^{-1} \mathrm{NaOH}$ (Allison and Moodie, 1965). Cation exchange capacity was determined by saturating the sorption complex with neutral ammonium acetate, washing the excess $\mathrm{NH}_{4}{ }^{+}$with ethanol and determining the adsorbed $\mathrm{NH}_{4}{ }^{+}$ion after quantitative removal by $\mathrm{K}^{+}$ions (Cottenie et al., 1982). Sediment pseudo-total metal contents were determined in the aqua regia extract (Ure, 1990).

Immediately after filtration, $\mathrm{pH}$ and electrical conductivity of the filtrates were measured using a potentiometer (Orion SA 720) and a conductivity meter (LF 537, WTF Weilheim, Germany), respectively. Total dissolved organic carbon content was measured with a carbon analyzer (Shimadzu, TOC 5000). Metal concentrations in the filtrates were measured using either a flame atomic absorption spectrophotometer (Varian SpectrAA 10) or a graphite furnace atomic absorption spectrophotometer (Varian SpectrAA-1475). External standard solutions were prepared from $1000 \mathrm{mg} \mathrm{L}^{-1}$ stock metal solutions (Merck) in the corresponding extracting solutions. Arsenic was measured with a flame atomic absorption spectrophotometer equipped 
with a hydride generator. Concentrations of metals in blank solution were below the detection limit of flame atomic absorption.

\section{RESULTS AND DISCUSSION}

\section{Chemical Characteristics of Sediments}

Selected chemical characteristics of LDDS used in this study are shown in Table 1. The $\mathrm{pH}$ values of these sediments were high, ranging from 6.9 to 8.2 , primarily due to the presence of carbonates (Table 1). Oxidation reaction may result in substantial acidification after upland disposal of dredged sediments, but the presence of carbonates efficiently buffered against a decrease in $\mathrm{pH}$ in these LDDS. The observed cation exchange capacity (CEC) values were in the normal range of mineral soils with similar texture and organic matter contents. Relatively low organic matter content was observed in sediment LG, which was disposed 12 years earlier, compared to the other two sediments, which were disposed of less than three year earlier. Organic matter tends to decrease with increasing disposal time. This may be related to fast decomposition of organic matter as a result of intense microbial activity and bioturbation by soil organisms under aerobic conditions.

Total metal contents in sediment LG were the lowest among the three sediments and fall within the ranges for normal soils in Belgium with a similar content of organic matter and clay (Tack et al., 1997b). In the case of sediments GH and MG, total metal contents were high for most metals investigated and exceeded the EC-limits for trace metals in agricultural soils to which sewage sludge is applied (European Community, 1986) and Dutch reference values by a factor of 5 to 10 (Leidraad Bodembescherming, 1988). Thus, sediments GH and MG were considered contaminated with trace metals whereas sediment LG was not. 


\section{Metal Distributions in Sediments}

Potential release of trace metals from contaminated sediments was estimated using a threestep sequential extraction procedure. For quality control, the analytical variability associated with these measurements was determined by applying the sequential extraction procedure on reference sediment (CRM 601). This sediment has been certified for the contents of $\mathrm{Cd}, \mathrm{Cr}, \mathrm{Cu}, \mathrm{Ni}, \mathrm{Pb}$ and $\mathrm{Zn}$ for the fractions involved in the three-step extraction procedure (Quevauviller et al., 1997). Sequential results obtained for CRM 601 overlapped its certified values (taking into consideration the relative standard deviation) for most investigated metals (Table 2). The only observed exceptions were for $\mathrm{Cr}$ and $\mathrm{Pb}$ concentration in the first step. Results of this quality performance evaluation demonstrated the reliability of laboratory analytical performance for the investigated trace metals.

The sequential extraction results for LDDS indicated wide variations of trace metal distribution in different fractions (Fig 1). Sequential extraction provides a refined operational assessment of metal association with various phases in the sediments. Following upland disposals, these sediments were subjected to drying and oxidation under an aerobic environment. According to Tack et al., (1997a), pH may have decreased due to the oxidation of sulfide, Fe/Mn oxides and decomposition of organic matter, but the presence of high carbonate efficiently buffered against decrease in the LDDS pH. Therefore, acid extractable, reducible and oxidizable fractions were considered important in evaluating metal mobility in LDDS. Higher metal concentrations in the first three fractions may indicate greater mobility of these metals in LDDS. 
Based on their distribution patterns, metals can be divided into three groups. Cadmium, Mn and $\mathrm{Zn}$ were less firmly bound since $>50 \%$ of their total contents were present in their acid extractable and reducible fractions (Fig. 1). This suggests that they were either sorbed on various solid phases or associated with carbonates and Fe-Mn oxides (Tessier et al., 1979; Kim and Fergusson, 1991). Metals such as Co and Ni were more evenly distributed between the first two and the last two fractions. Chromium, $\mathrm{Cu}$ and $\mathrm{Pb}$ were largely associated with the oxidizable and residual fractions, which accounted together for $>80 \%$ of total contents. No sulfides were present in these oxidized upland disposal environments. Metals in the oxidizable fractions, therefore, were presumably associated primarily with organic matter (Hickey and Kittrick, 1984; Kim and Ferguson, 1991).

Although the investigated LDDS differed in their origin and disposal times, the observed similarities in their metal distribution patterns suggests that metal accumulation and transformation processes were similar. Sediments MG and LG originated from the same canal (Deviation canal from the River Lys), but these were dredged and disposed at different times. Sediment GH was from different inland water (Canal Gent-Terneuzen with brackish water and located in the industrial area). Even though sediment GH was disposed only one year before our sampling, it exhibited similar distribution patterns with the other two investigated sediments. This illustrates that major changes in metal distribution resulting from oxidation can occur within a short period after their upland disposals. Therefore, sediment sources and length of their disposal time beyond one year was not a major factor to influence the metal distribution patterns in the studied LDDS. Tack et al., (1996) also observed pronounced differences in metal leaching between reduced sediment and sediment that was gradually dried and oxidized. 


\section{Trace metal Leachability in Sediments}

Leaching is a complex phenomenon since many factors may influence the release of trace metals from LDDS. The major geochemical factors controlling metal release in sediments include $\mathrm{pH}$, redox potential, organic matter content, complexation, and biological activity (Bourg and Loch, 1995; Förstner, 1995; Van der Sloot et al., 1996).

\section{Potential Leachability}

The potentially leachable metal contents represent the fraction that may become available for leaching under normal environmental conditions (Van der Sloot, 1991). Concentrations of potentially leachable trace metals determined by the standard leaching method (NEN 7341, 1994) are presented in Table 3. Cadmium, Co, Mn, Ni and $\mathrm{Zn}$ (19-82\% of total metal content) had relatively higher leaching potential compared to $\mathrm{As}, \mathrm{Cr}, \mathrm{Cu}$ and $\mathrm{Pb}(<1-18 \%$ of total metal content). Averaged over all sediments, potential leachability (expressed as the percentage of total metal content) decreased in the order: $\operatorname{Zn}(61 \%)>\operatorname{Cd}(60 \%)>\operatorname{Mn}(53 \%)>\operatorname{Co}(27 \%)>\operatorname{Ni}(26 \%)>$ As $(14 \%)>\mathrm{Cu}(4 \%)>\mathrm{Pb}(2 \%)>\mathrm{Cr}(2 \%)$. Observed metal releases were significantly higher in the contaminated sediments ( $\mathrm{GH}$ and $\mathrm{MG}$ ) compared to the relatively uncontaminated sediment LG.

At a constant $\mathrm{pH}$ 4, we observed a high potential release of $\mathrm{Zn}, \mathrm{Cd}, \mathrm{Mn}$, Co and Ni (Table 3), which was consistent with our metal distribution data (Fig. 1). Carbonates and Fe-Mn oxides may be considered a major solubility controlling solid phase for these metals (Eary et al., 1990, Lee and Touray, 1998). In fractionation, we observed that a large proportion of $\mathrm{Zn}, \mathrm{Cd}, \mathrm{Mn}, \mathrm{Co}$ and $\mathrm{Ni}$ in the sediments were present in the acid extractable and reducible fractions. In an upland disposal 
environment, trace metal solubility as a function of $\mathrm{pH}$ is directly related to $\mathrm{pH}$-controlled dissolution and desorption processes, which may also involve initially present sediment phases and/or phases formed during subsequent drainage and oxidation of the sediment (Tack et al., 1996). On the other hand, the low potential leachability for $\mathrm{As}, \mathrm{Cu}, \mathrm{Pb}$ and $\mathrm{Cr}$ were consistent with metal distribution data (Fig. 1). Under oxidized or moderately reduced acidic environments, As and Cr exist in less soluble oxidation states (Masscheleyn et al., 1991; 1992). Copper and to a lesser extent $\mathrm{Pb}$, are capable of forming complexes with organic matter and these complexes remain stable even below pH 3 (Brümmer, 1986; Lievens, 1991). Kinniburgh et al. (1976) observed a 50 \% retention of $\mathrm{Cu}$ and $\mathrm{Pb}$ on iron oxide at $\mathrm{pH} 4.1$ and 3.2, respectively. Strong adsorption / readsorption on clay minerals may also contribute towards their strong retention.

\section{Relationship between Potential Leachability and Sequential Extraction}

Significant regression equations between trace metal potential leachability and individual metal fractions obtained from the sequential extractions are listed in the Table 4. For this Regression In general, the acid extractable fraction (F1) was consistently correlated with potential leachability with the exception of $\mathrm{Pb}$, where the oxidizable fraction remained highly significant. For $\mathrm{Cd}, \mathrm{Co}$, $\mathrm{Cu}, \mathrm{Mn}, \mathrm{Ni}$, and $\mathrm{Zn}$ the concentrations in the acid extractable fraction seemed to provide the best estimate of their potential leachability in LDDS. Because of similar geochemical behavior, $\mathrm{Cd}$ and $\mathrm{Zn}$ can be dissolved more easily than $\mathrm{Pb}$ during the test for potential leachability because acidic conditions easily destroy carbonates and release carbonate associated trace metals (Tack and Verloo, 1996). However, in case of Cr no sequential fraction showed significant relationship with 
its potential leachability. Using total sediment metal contents in the regression equations failed to improve the estimation of potential leachability in LDDS. Therefore that variable was not incorporated in the regression equation.

\section{Actual Leachability}

All fractions obtained from the Cascade Leaching Test (CLT) were characterized by neutral to slightly alkaline $\mathrm{pH}$-values, which is directly related to the presence of $\mathrm{CaCO}_{3}$ in these $\mathrm{LDDS}$ (Table 5). The leachate $\mathrm{pH}$ increased slightly with increasing cumulative $\mathrm{L} / \mathrm{S}$ ratio. For all sediments, electrical conductivities remained high in the earlier leachates, especially for sediment MG, but dropped sharply in consecutive fractions indicating a rapid leaching of soluble salts. Initial soluble organic carbon content was low and decreased slightly in subsequent fractions.

The concentrations of metals released in the CLT fractions varied among metals (Table 6). Concentrations of metals (particularly $\mathrm{Ni}$ and $\mathrm{Zn}$ ) were relatively high in the first fractions and decreased in subsequent fractions indicating rapid leaching of soluble metals. Concentrations of As, $\mathrm{Cu}, \mathrm{Cr}$ and $\mathrm{Ni}$ in the leachate from contaminated sediments $\mathrm{GH}$ and MG were close to the Netherlands Standard A reference values for surface and ground water (Leidraad Bodemsanering, 1988).

Observed metal concentrations in leachates from contaminated sediments $\mathrm{GH}$ and MG were high compared to the non contaminated sediment LG. Metal concentrations in all consecutive leaching fractions remained below the maximum permissible levels in water intended for human consumption (Smeets and Amovis, 1981). Nevertheless, trace metals released from contaminated LDDS were elevated in terms of absolute amounts as compared to uncontaminated LDDS. 
Relative to the potential leachable amounts, leached quantities from the contaminated sediments were low.

The cumulative leachability of trace metals from LDDS at any liquid solid ratio (L/S) was obtained by summing the actual leached metal contents up to the L/S ratio considered. The cumulative leaching behavior is plotted as a percentage of their potential leachable metal pool in Fig. 2. In general, the cumulative leaching percentage (average of cumulative leaching percentages at a L/S ratio 100) decreased in the order: As $(40 \%)>\mathrm{Cu}(21 \%)>\mathrm{Cr}(18 \%)>\mathrm{Ni}(6 \%)>\mathrm{Zn}(4$ $\%)>\mathrm{Cd}(2 \%)=\mathrm{Pb}(2 \%)$. For $\mathrm{Cd}, \mathrm{Pb}$ and $\mathrm{Zn}$, only small fractions of the potentially leachable metal pools were released into the CLT solution (Fig. 2). The cumulative leachability thus remained minimal, although these metals were characterized by their large potentially mobile metal pools.

The observed low leachability in LDDS was attributable to several factors. Sorption is a potentially important mechanism in controlling leaching of $\mathrm{Cd}, \mathrm{Co}, \mathrm{Cu}, \mathrm{Ni}, \mathrm{Zn}$, and $\mathrm{Pb}$. Reactive sorbent minerals such as Fe / Mn / Al-(hydr)oxides are present in large amounts in LDDS and these metals have high affinity for Fe / Mn / Al -(hydr)oxides (Kinniburgh et al., 1976). In addition, the neutral to slightly alkaline $\mathrm{pH}$ of the sediments favored strong adsorption of these metals on oxides and hydroxides of iron and manganese as well as on the clay mineral surfaces (Brümmer, 1986; Yong et al., 1990). Sorption of these minerals is qualitatively consistent with observed leaching patterns, the affinity of metals for these minerals increasing with increasing $\mathrm{pH}$. Sawhney et al. (1995) also reported minimum leachability of metals ( $\mathrm{Cd}, \mathrm{Co}, \mathrm{Cu}, \mathrm{Ni}$ and $\mathrm{Zn})$ from a compost amended growth medium when leachate $\mathrm{pH}$ remained near neutral. High carbonate contents and its strong buffering effects (Table 1) played a significant role in delaying and limiting the leaching reaction of trace metals in the contaminated sediments. Moreover, fresh calcite may also precipitate 
because of carbonation, which may also affect leaching of $\mathrm{Cd}$ and $\mathrm{Zn}$ due to their high affinity for calcite (Meima and Comans, 1999).

In contrast, the actual release of $\mathrm{As}, \mathrm{Cr}$ and $\mathrm{Cu}$ were high in all three sediments although these metals were characterized by a relatively small pool of potentially leachable metals. The high actual leachability of As and $\mathrm{Cr}$ under oxidized conditions may be explained by their enhanced solubility and low adsorption in the neutral to slightly alkaline environment. According to Meima and Comans (1999), the affinity of oxyanion sorption on Fe /Mn / Al-(hydr) oxides minerals increases with decreasing $\mathrm{pH}$. The high leachability of $\mathrm{Cu}$ in neutral to slightly alkaline medium can be related to its strong complexation with DOC (Tyler, 1981; Van der Sloot et al., 1992). Compared to the other metals, the leachability of $\mathrm{Pb}$ was low and remained unaffected even though deionized water acidified to $\mathrm{pH} 4$ was used in the leaching test. This particular behavior can be explained by strong $\mathrm{Pb}$ adsorption/readsorption by the sediment at neutral $\mathrm{pH}$.

The percentage of potential leachable metals released into the CLT solution remained lower in the contaminated sediments, GH and MG, than in relatively uncontaminated sediment, LG (Fig.2). According to Gambrell (1994), an excess of metals in the contaminated soils becomes primarily associated with potentially available forms (metals precipitated as inorganic compounds, complexed with large molecular-weight humic materials or adsorbed or occluded to precipitated hydrous oxides) rather than readily available forms (water-soluble and exchangeable). Tyler (1978) explained that the low metal leachability in contaminated forest soils was due to blocking of exchange sites with metal ions and competitive sorption because of increased metals in the soil solution. During the actual leachability tests, no major physicochemical changes occurred in 
dredged sediment characteristics. Therefore metal leaching in field conditions can be expected to occur slowly but steadily.

Adverse environmental impacts due to metal leaching from land disposed contaminated dredged sediments may be negligible compared to the environmental and economical drawbacks of confined disposal. However, released metal concentrations remained higher than background concentrations in surface and ground water and may lead to their enhanced accumulation in soil organisms compared to an unpolluted environment. Specific field situations can be evaluated by using leaching data as an input parameter to assess the extent of metal migration (Tack et al., 1993; Tack et al., 1999). Alternative utilization of dredged sediments in landscape restorations, agriculture and construction should be allowed only when these effects are considered acceptable.

\section{CONCLUSIONS}

Trace metal leachability from land disposed dredged sediments played a significant role in determining their potential environmental risk to surrounding surface and ground water contamination. The sequential extraction studies revealed that carbonates and Fe-Mn oxides in dredged sediment acted as major scavengers for $\mathrm{Cd}, \mathrm{Co}, \mathrm{Mn}, \mathrm{Ni}$, and $\mathrm{Zn}$. Organic matter appeared to be an important carrier for $\mathrm{Cr}, \mathrm{Cu}$ and $\mathrm{Pb}$. Potential and actual leachability varied widely among metals in the sediments studied. Potential leachability expressed as a percentage of total metal content decreased in the order: $\mathrm{Zn}>\mathrm{Cd}>\mathrm{Mn}>\mathrm{Co}>\mathrm{Ni}>\mathrm{As}>\mathrm{Cu}>\mathrm{Pb}>\mathrm{Cr}$. Based on the foregoing discussion, a significant relationship exists between potential leachability and fractions determined by sequential extractions. Total metal content was a poor indicator of potential metal leachability in the LDDS. Metal concentrations, except for Ni and Zn, in the first 
fraction of the actual leachability test were close to the reference value for surface and ground water. The cumulative leachability (expressed as percentage of potentially leachable metal pool) decreased in the order: $\mathrm{As}>\mathrm{Cu}>\mathrm{Cr}>\mathrm{Ni}>\mathrm{Zn}>\mathrm{Cd}>\mathrm{Co}>\mathrm{Pb}$. Although the sequential extraction procedure is operationally defined, it was a useful tool for the prediction of trace metal leachability from LDDS. Measured leaching data indicated a low risk for surface and ground water contamination from LDDS.

\section{REFERENCES}

Allison, L.E. 1965. Organic carbon. p. 1367-1378. In: C.A. Black et al. (ed.) Methods of soil analysis. Part 2. Chemical and microbiological properties, ASA, Madison, WI, USA.

Allison, L. E. and C.D. Moodie. 1965. Carbonates. p. 1379-1396. In: C.A.Black et al. (ed.) Methods of soil analysis. Part 2. Chemical and microbiological properties, ASA, Madison, WI, USA.

Belzile, N., N. Lecomte, and A. Tessier. 1989. Heavy metal extractability in long term sewage sludge amended soils. Environ. Sci. Technol. 23:1015-1020.

Bourg, A.C.M. and J.P.G. Loch. 1995. Mobilization of heavy metals as affected by pH and redox conditions. p.87-102. In: W. Salomons and W.M. Stigliani (ed.) Biogeodynamics of pollutants in soils and sediments. Springer Verlag, New York.

Bridle, T.R., P.L. Côtè, T.W. Constable and J.L. Fraser. 1987. Evaluation of heavy metal leachability from solid wastes. Water Sci. Tech. 19:1029-1036. 
Brümmer, G.W. 1986. Heavy metal species, mobility and availability in soils. p.69-192. In: M. Bernhard et al. (ed.) The importance of chemical "speciation" in chemical processes. Springer Verlag, New York.

Bubb, J.M. and J.N. Lester. 1991. Impact of heavy metals on low land rivers and implications for the man and the environment. Sci. Total Environ. 100:207-258.

Cottenie, A., M. Verloo, L. Kiekens, G. Velghe, and R. Camerlynck. 1982. Chemical analysis of plants and soils. IWONL, Brussels, 63 pp.

Demoen, J. 1989. Naar een nieuwe aanpak van de berging van onderhoudsbaggerspecie van de bevaarbare waterlopen. Water. 47:117-120.

Eary, L.E., D. Rai, S.V. Mattigod, and C.C. Ainsworth, C.C. 1990. Geochemical factors controlling the mobilization of inorganic constituents from fossil fuels combustion residues: II Review of minor elements. J. Environ. Qual. 19:202-214.

Eighmy, T.T., J.D. Eusdon Jr., J.E. Krazanowski, D.S. Domingo, D. Stampfli, J.R. Martin, and P.M. Erikson. 1995. Comprehensive approach toward understanding element speciation and leaching behavior of in municipal solid waste incineration electrostatic precipitator ash. Environ. Sci. Technol. 29:629-646.

European Community (EC), 1986. Directive on the protection of the environment and in particular of soils, when sewage sludge is used in agriculture. Directive 86/276/EEC, Official Journal of European Community, L181 4/7/1986, European Community, Brussels. 
Förstner, U. 1993. Metal speciation - general concepts and applications. Int. J. Anal. Chem. $51: 5-23$.

Förstner, U. 1995. Non linear release of metals from the aquatic sediments. P. 247-307. In: W. Salomons and W.M. Stigliani (ed.) Biogeodynamics of pollutants in soil and sediment. Springer Verlag, New York.

Gambrell, R.P. 1994. Trace and toxic metals in wetland. J. Environ. Qual., 23, 883-891.

Hickey, M.G. and Kittrick, J.A. 1984. Chemical portioning of cadmium, copper, nickel, and zinc in soils and sediments containing high levels of heavy metals. J. Environ. Qual. 13:372-376.

Kim, N.D. and J.E. Fergusson, 1991. Effectiveness of a commonly used sequential extraction techniques in determining the speciation of cadmium in soils. Sci. Total Environ. 105:191209.

Kinniburgh, D.G., M.L. Jackson, and J.K. Syres, J. K. 1976. Adsorption of alkaline earth, transition and heavy metal cations by hydrous oxide gels of iron and aluminum. Soil Sci. Soc. Am. J. 40:796-799.

Lee, P.K. and J.C. Touray, 1998. Characteristics of a polluted soils located along a motorway and effects of acidification on the leaching behavior of heavy metals ( $\mathrm{Pb}, \mathrm{Zn}, \mathrm{Cd})$. Water Res. $32: 3425-3435$.

Leidraad Bodembescherming. 1988. VROM, s-Gravenshage, The Netherlands. 
Lievens, F.R. 1991. Chemical reactions of metals with humic material. Environ. Pollut. 70:183208.

Ma, L.Q. and G.N. Rao, 1997. Chemical fractionation of cadmium, copper, nickel and zinc in contaminated soils. J. Environ. Qual. 26:259 - 264.

Maskell, J.E. and I. Thornton, 1998. Chemical partitioning of heavy metals in soil rock at historical lead smelter site. Water Air Soil Pollut. 108:391-409.

Masscheleyn, P.H., R.D. Delaune, and W.H. Patrick Jr.,1991. Arsenic and selenium chemistry as affected by sediment redox potential and pH. J. Environ. Qual. 20:522-527.

Masscheleyn, P.H., R.D. Delaune and W.H. Patrick Jr., 1992. Chromium redox chemistry in lower Mississippi valley bottomland hardwood wetland. Environ. Sci. Technol. 26:12171225.

Meima, J.A. and R.N.J. Comans, 1999. The leaching of trace elements from municipal solid waste incinerator bottom ash at different stages of weathering. Applied Geochemistry, $14: 159-171$.

Moore, J.N., W.H. Ficklin, and C. Johns. 1988. Partitioning of arsenic and metals in sulfidic reducing sediments. Environ. Sci. Technol. 22:432-437. 
NEN 7341 1994. Determination of availability for leaching of inorganic components from granular (wastes) material. The Netherlands Energy Research Foundation, Final version, July 1994.

Quevauviller, P., G. Rauret, H. Muntau, A.M. Ure, J.F. López-Sánchez, H.D. Fiedler, and B. Griepink. 1994. Evaluation of sequential extraction procedure for determination of extractable trace metal contents in dredged sediments. Fresenius J. Anal. Chem. 349:808814.

Quevauviller, P., M. Lachica, B. Barahona, G. Rauret, A.M. Ure, A. Gomez, A. and H. Muntau. 1996. Inter laboratory comparison of EDTA and DTPA procedures prior to certification of extractable trace elements in calcareous soils. Sci. Total Environ. 178:127-132.

Quevauviller P., G. Rauret, J.F. Lopez-Sanchez, R. Rubio, A. Ure, and H. Muntau. 1997. Certification of trace metal Extractable contents in a Sediment reference material (CRM 601) following a three-step sequential extraction procedure. Sci. Tot. Environ. 205:223-234.

Rapin, F., A. Tessier, P.G.C. Campbell, and R.Carignan. 1986. Potential artifacts in the Determination of metal partitioning in sediments by a sequential extraction procedure. Environ. Sci. Technol. 20:836-40.

Sawhney, B.L., G.J. Bugbee and D.E. Stilwell. 1995. Heavy metal leachability as affected by pH of composted-amended growth medium used in container-grown Rhododendrons. Compost Sci. Utilization. 3:64-73. 
Smeets, J. and R. Amovis, 1981. European community directive relation to the quality of water intended for human consumption. Water Air Soil Pollut. 15:483-502.

Tack, F. and M. Verloo. 1991. Estimation and testing of environmental effects of heavy metals in dredged materials. p. 3:55-3.59.In Proc. CATS Congress I, K.VIV, Antwerpen, Belgium.

Tack, F.M.G. and M.G. Verloo. 1993. Leaching behavior and chemical fractionation of selected metals as affected by thermal treatment of polluted sediments. Int. J. Environ. Anal. Chem. $51: 167-175$.

Tack, F.M.G., P.H. Masscheleyn, and M.G. Verloo. 1993. Leaching behavior of granulated nonferrous metal slags. p. 103-117. In: J. P. Vernet (ed), Environmental contamination, Elsevier Pub. Amsterdam, The Netherlands.

Tack, F.M.G. and M.G. Verloo. 1995. Chemical speciation and fractionation in soil and sediment heavy metal analysis. Int. J. Environ. Anal. Chem. 59:225-238.

Tack, F.M.G. and M.G. Verloo. 1996. Estimated solid phase distribution of metals released in the acid extractable and reducible steps of a sequential extraction. Int. J. Environ. Anal. Chem. 64:171-177.

Tack, F.M.G., O.W.J.J. Callewaert and Verloo, M.G. 1996. Metal solubility as a function of pH in a contaminated, dredged sediment affected by oxidation. Environ Pollut. 91:199-206. 
Tack, F. M., F. Lapauw, and M. G. Verloo. 1997a. Determination and fractionation of sulphur in a contaminated dredged sediment. Talanta 44:2185-2192.

Tack, F. M. G., M. G. Verloo, L. Vanmechelen, and E. Van Ranst. 1997b. Baseline concentration levels of trace elements as a function of clay and organic carbon contents in soils in Flanders (Belgium). Sci. Total Environ. 201:113-23.

Tack, F. M. G., S. P. Singh, and M. G. Verloo. 1999. Leaching behavior of Cd, Cu, Pb and Zn in surface soils derived from dredged sediments. Environ. Pollut. 106:107-14.

Tessier, A., P.G.C. Campbell and M. Bisson. 1979. Sequential extraction procedure for the speciation of particulate trace metals. Anal. Chem. 51:844-851.

Tyler, G. 1978. Leaching rate of heavy metals in forest soils. Water Air Soil Pollut. 9:137-148.

Tyler, G. 1981. Leaching of metals from the A-horizon of spruce forest soil. Water Air Soil Pollut. 15:353-357.

Ure, A.M.1990. Methods of analysis for heavy metals in soils. pp. 40-73. In B.J. Alloway (ed.), Heavy Metals in Soils. Blackie and Son, Glasgow.

Utermann, J, O. Düwel, H. E. Gäbler, and R. Hindel. 1999. Substrate- and element specific relation of real total versus Aqua Regia soluble contents of heavy metals in soils. p. 406-407. In: W. W. Wenzel, et al. (ed.) Proc. 5th Int. Conf. Biogeochemistry of Trace Elements, Vienna, Austria. 11 Jul-15 Jul. 1999. 
Van der Sloot, H.A. 1991. Systematic leaching behavior of trace elements from construction materials and waste materials. Tech. Report ECN RX 91-088, Netherlands Energy Research Foundation.

Van der Sloot, H.A, R.N.J. Comans, T.T. Eighmy, and D.S. Kosson, 1992. Interpretation of MSWI residue leaching data in relation to utilization and disposal. Tech. Report ECN RX 92-051, Netherlands Energy Research Foundation.

Van der Sloot, H.A., R.N.J. Comans, and O. Hjelmer. 1996. Similarities in the leaching behavior of trace contaminants from waste, stabilized waste, construction materials and soils. Sci. Total Environ. 178:111-126.

Yong, R.N., B.P. Werkentin, Y. Phadungchewit, and R. Galvez. 1990. Buffer capacity and lead retention in some clay materials. Water Air Soil Pollut. 53:53-67. 


\section{FIGURE CAPTIONS}

Fig.1. Solid phase distribution of trace metals in land disposed dredged sediments (Sediment GH, $\mathrm{MG}$, and LG respectively)

Fig.2. Amounts of trace metals released (expressed as percentage of potentially leachable metal contents) from land disposed dredged sediments in function of increasing cumulative liquid solid ratio (curves represent logarithmic fits of data) 
Table 1. Chemical characteristics of the three land disposed dredged sediments used in this study

\begin{tabular}{lccc}
\hline \multicolumn{1}{c}{ Parameter } & Sediment $\mathrm{GH}$ & Sediment $\mathrm{MG}$ & Sediment LG \\
\hline $\mathrm{pH} \mathrm{H}{ }_{2} \mathrm{O}$ & 6.9 & 7.2 & 8.2 \\
Organic carbon $\left(\mathrm{g} \mathrm{Kg}^{-1}\right)$ & 45.9 & 55.2 & 5.2 \\
$\mathrm{CaCO}_{3}\left(\mathrm{~g} \mathrm{Kg}^{-1}\right)$ & 71.0 & 78.4 & 10.2 \\
$\mathrm{CEC}\left(\mathrm{cmole} \mathrm{kg}^{-1}\right)$ & 21 & 30 & 6.6 \\
\hline
\end{tabular}

Trace metals $\left(\mu \mathrm{g} \mathrm{g}^{-1}\right)$

\begin{tabular}{lrrr}
\hline $\mathrm{As}$ & $47 \pm 3.0^{*}$ & $29 \pm 2.0$ & $3.7 \pm 0.3$ \\
$\mathrm{Cd}$ & $11 \pm 0.2$ & $17 \pm 2.0$ & $1.3 \pm 0.4$ \\
$\mathrm{Co}$ & $22 \pm 3.0$ & $22 \pm 2.0$ & $11 \pm 3.0$ \\
$\mathrm{Cr}$ & $388 \pm 35$ & $323 \pm 5.0$ & $15 \pm 1.0$ \\
$\mathrm{Cu}$ & $158 \pm 1.0$ & $210 \pm 21$ & $7.7 \pm 0.1$ \\
$\mathrm{Mn}$ & $741 \pm 14$ & $394 \pm 30$ & $154 \pm 5.0$ \\
$\mathrm{Ni}$ & $46 \pm 3.0$ & $102 \pm 1.0$ & $18 \pm 3.0$ \\
$\mathrm{~Pb}$ & $322 \pm 2.0$ & $274 \pm 14$ & $14 \pm 5.0$ \\
$\mathrm{Zn}$ & $1338 \pm 34$ & $1447 \pm 90$ & $38 \pm 12$ \\
\hline
\end{tabular}

* Mean \pm standard deviation of three replicate analyses 
Table 2. Laboratory performance evaluation for the BCR-three step sequential extraction procedure on reference material CRM 601(concentration $\mathrm{mg} \mathrm{kg}^{-1}$ dry weight).

\begin{tabular}{lllllll}
\hline & $\mathrm{Cd}$ & $\mathrm{Cr}$ & $\mathrm{Cu}$ & $\mathrm{Ni}$ & $\mathrm{Pb}$ & $\mathrm{Zn}$ \\
\hline First step & & & & & & \\
Observed $^{\mathrm{a}}$ & $3.88 \pm 0.43$ & $0.45 \pm 0.07$ & $8.86 \pm 0.36$ & $8.47 \pm 0.51$ & $3.41 \pm 0.49$ & $256 \pm 20$ \\
Certified & $4.14 \pm 0.23$ & $0.36 \pm 0.04$ & $8.32 \pm 0.46^{\mathrm{b}}$ & $8.01 \pm 0.73$ & $2.68 \pm 0.35$ & $264 \pm 5$ \\
Second step & & & & & & \\
Observed & $2.84 \pm 0.21$ & $1.21 \pm 0.71$ & $7.06 \pm 0.74$ & $6.93 \pm 0.68$ & $25.5 \pm 2.5$ & $179 \pm 14$ \\
Certified & $3.08 \pm 0.17$ & $\mathrm{c}$ & $\mathrm{c}$ & $6.05 \pm 1.09$ & $33.1 \pm 10$ & $182 \pm 11$ \\
Third step & & & & & & \\
Observed & $2.17 \pm 0.10$ & $21.8 \pm 1.5$ & $160.3 \pm 5$ & $9.60 \pm 0.30$ & $107 \pm 0.7$ & $161 \pm 3$ \\
Certified & $1.83 \pm 0.20$ & $\mathrm{c}$ & $\mathrm{c}$ & $8.55 \pm 1.04$ & $109 \pm 13$ & $\mathrm{c}$ \\
\hline
\end{tabular}

${ }^{\mathrm{a}}$ Mean \pm standard deviation of three replicate analyses

${ }^{\mathrm{b}}$ Indicative value

${ }^{\mathrm{c}}$ not certified 
Table 3. Potential leachable metal contents in studied land disposed dredged sediments $\left(\mathrm{mg} \mathrm{kg}^{-1}\right.$ air dry LDDS and $\%$ of the total content).

\begin{tabular}{|c|c|c|c|c|c|c|}
\hline \multirow[b]{2}{*}{ Metal } & \multicolumn{2}{|c|}{ Sediment GH } & \multicolumn{2}{|c|}{ Sediment MG } & \multicolumn{2}{|c|}{ Sediment LG } \\
\hline & $\mathrm{mg} \mathrm{kg}^{-1}$ & $\%$ & $\mathrm{mg} \mathrm{kg}^{-1}$ & $\%$ & $\mathrm{mg} \mathrm{kg}^{-1}$ & $\%$ \\
\hline As & $6.2 \pm 0.2^{*}$ & $14 \%$ & $2.5 \pm 0.0$ & $9 \%$ & $0.6 \pm 0.1$ & $\begin{array}{l}18 \\
\%\end{array}$ \\
\hline $\mathrm{Cd}$ & $8.9 \pm 0.2$ & $82 \%$ & $7.5 \pm 0.2$ & $44 \%$ & $0.7 \pm 0.1$ & $\begin{array}{l}53 \\
\%\end{array}$ \\
\hline $\mathrm{Co}$ & $6.8 \pm 0.3$ & $31 \%$ & $4.2 \pm 0.6$ & $19 \%$ & $3.1 \pm 0.1$ & $\begin{array}{l}31 \\
\%\end{array}$ \\
\hline $\mathrm{Cr}$ & $3.4 \pm 0.1$ & $<1 \%$ & $1.7 \pm 0.1$ & $<1 \%$ & $0.7 \pm 0.1$ & $5 \%$ \\
\hline $\mathrm{Cu}$ & $3.4 \pm 0.1$ & $2 \%$ & $16.4 \pm 3.7$ & $8 \%$ & $2.3 \pm 0.1$ & $2 \%$ \\
\hline $\mathrm{Mn}$ & $423 \pm 29$ & $57 \%$ & $93.6 \pm 2.4$ & $24 \%$ & $118 \pm 3.0$ & $\begin{array}{l}77 \\
\%\end{array}$ \\
\hline $\mathrm{Ni}$ & $13.1 \pm 1.4$ & $28 \%$ & $22.6 \pm 0.6$ & $22 \%$ & $4.8 \pm 0.4$ & $\begin{array}{l}27 \\
\%\end{array}$ \\
\hline $\mathrm{Pb}$ & $6.8 \pm 0.9$ & $2 \%$ & $6.3 \pm 1.9$ & $2 \%$ & $0.6 \pm 0.1$ & $2 \%$ \\
\hline $\mathrm{Zn}$ & $885 \pm 18$ & $66 \%$ & $713 \pm 2$ & $49 \%$ & $18.2 \pm 0.7$ & $\begin{array}{l}66 \\
\%\end{array}$ \\
\hline
\end{tabular}

*. Mean \pm standard deviation of three replicate analyses 
Table 4. Regression equations for trace metal potential leachability in LDDS as related to their concentrations in various fractions estimated by the sequential extraction procedure (Note: Data for regression analysis includes 4 additional LDDS samples).

\begin{tabular}{ccc}
\hline \multicolumn{1}{c}{ Metals } & Regression Equations & $\mathrm{R}^{2}$ \\
\hline $\mathrm{Cd}$ & ${ }^{\dagger} Y_{P L}=0.2 .08+0.74 F_{\text {Acid Extractable }}$ & $0.669^{*}$ \\
$\mathrm{Co}$ & $Y_{P L}=-1.29+1.15 F_{\text {Acid Extractable }}$ & \\
$\mathrm{Cr}$ & $Y_{P L}=1.324+0.90 F_{\text {Acid Extractable }}$ & $0.977^{* *}$ \\
$\mathrm{Cu}$ & $Y_{P L}=10.58+0.88 F_{\text {Acid Extractable }}$ & 0.622 \\
$\mathrm{Mn}$ & $Y_{P L}=3.159+0.587 F_{\text {Acid Extractable }}$ & $0.98^{* *}$ \\
$\mathrm{Ni}$ & $Y_{P L}=1.001+0.0396 F_{\text {Oxidizable }}$ & $0.840^{*}$ \\
$\mathrm{~Pb}$ & $Y_{P L}=19.508+1.09 F_{\text {Acid Extractable }}$ & $0.925^{* *}$ \\
$\mathrm{Zn}$ & & $0.947^{* *}$ \\
\end{tabular}

*** Significant at the 0.05 and 0.01 probability levels respectively

${ }^{\dagger} \mathrm{Y}_{\mathrm{PL}}$ Potential leachability 
Table 5. $\mathrm{pH}$, electrical conductivity and dissolved organic carbon concentrations in cascade leaching fractions (NEN 7341) at different cumulative liquid to solid ratios (L/S ratio) in the studied LDDS.

\begin{tabular}{|c|c|c|c|c|c|}
\hline L/S Ratio & 20 & 40 & 60 & 80 & 100 \\
\hline \multicolumn{6}{|c|}{$\mathrm{PH}$} \\
\hline $\mathrm{GH}$ & $7.63 \pm 0.05^{*}$ & $7.78 \pm 0.03$ & $7.89 \pm 0.00$ & $7.84 \pm 0.03$ & $7.84 \pm 0.08$ \\
\hline $\mathrm{MG}$ & $7.28 \pm 0.03$ & $7.72 \pm 0.11$ & $7.92 \pm 0.14$ & $7.91 \pm 0.20$ & $8.05 \pm 0.07$ \\
\hline LG & $7.87 \pm 0.00$ & $7.93 \pm 0.01$ & $7.88 \pm 0.06$ & $7.83 \pm 0.06$ & $7.96 \pm 0.06$ \\
\hline \multicolumn{6}{|c|}{ Electrical conductivity $\left(\mu \mathrm{S} \mathrm{cm}^{-1}\right)$} \\
\hline $\mathrm{GH}$ & $732 \pm 4$ & $249 \pm 2$ & $186 \pm 3$ & $213 \pm 3$ & $153 \pm 6$ \\
\hline MG & $1026 \pm 24$ & $214 \pm 6$ & $128 \pm 5$ & $118 \pm 9$ & $102 \pm 5$ \\
\hline $\mathrm{LG}$ & $202 \pm 7$ & $93 \pm 2$ & $87 \pm 3$ & $87 \pm 3$ & $89 \pm 0$ \\
\hline \multicolumn{6}{|c|}{ Dissolved organic carbon $\left(\mathrm{mg} \mathrm{L}^{-1}\right)$} \\
\hline $\mathrm{GH}$ & $21.2 \pm 0.8$ & $16.8 \pm 1.3$ & $18.0 \pm 2.7$ & $15.8 \pm 1.0$ & $12.7 \pm 2.4$ \\
\hline $\mathrm{MG}$ & $22.9 \pm 1.5$ & $17.6 \pm 0.7$ & $16.3 \pm 0.5$ & $15.7 \pm 1.6$ & $12.4 \pm 1.1$ \\
\hline LG & $12.8 \pm 0.1$ & $8.8 \pm 0.2$ & $7.9 \pm 0.1$ & $7.9 \pm 0.3$ & $8.4 \pm 1.2$ \\
\hline
\end{tabular}


Table 6. Trace metal concentrations in cascade leaching fractions (NEN 7341) at different cumulative liquid to solid ratios (L/S ratio) in the studied LDDS

\begin{tabular}{lccccc}
\hline \multicolumn{5}{c}{ Metal concentration $\left(\mu \mathrm{g} \mathrm{L}^{-1}\right)$} \\
\hline $\mathrm{L} / \mathrm{S}$ Ratio & 20 & 40 & 60 & 80 & 100 \\
\hline \multicolumn{5}{c}{ Sediment GH } \\
$\mathrm{As}$ & $17.5 \pm 0.7$ & $21.6 \pm 2.5$ & $16.6 \pm 1.0$ & $16.6 \pm 2.3$ & $12.1 \pm 4.7$ \\
$\mathrm{Cd}$ & $1.1 \pm 0.4$ & $0.7 \pm 0.1$ & $0.7 \pm 0.3$ & $0.5 \pm 0.1$ & $0.5 \pm 0.1$ \\
$\mathrm{Co}$ & $6.4 \pm 0.3$ & $2.5 \pm 0.3$ & $2.0 \pm 0.4$ & $1.6 \pm 0.5$ & $0.9 \pm 0.1$ \\
$\mathrm{Cr}$ & $3.8 \pm 0.1$ & $4.3 \pm 0.4$ & $3.6 \pm 0.1$ & $1.5 \pm 0.2$ & $1.4 \pm 0.1$ \\
$\mathrm{Cu}$ & $13.9 \pm 0.8$ & $10.3 \pm 1.4$ & $7.7 \pm 1.6$ & $7.9 \pm 1.0$ & $6.8 \pm 2.1$ \\
$\mathrm{~Pb}$ & $0.8 \pm 0.1$ & $0.7 \pm 0.2$ & $0.6 \pm 0.0$ & $0.2 \pm 0.1$ & $0.1 \pm 0.1$ \\
$\mathrm{Ni}$ & $17.0 \pm 2.6$ & $9.8 \pm 0.2$ & $7.4 \pm 1.4$ & $4.1 \pm 1.1$ & $2.8 \pm 0.4$ \\
$\mathrm{Zn}$ & $127 \pm 6$ & $82 \pm 4$ & $75 \pm 5$ & $90 \pm 5$ & $85 \pm 4$ \\
\hline & & $\mathrm{Sediment} \mathrm{MG}$ & & \\
$\mathrm{As}$ & $7.2 \pm 0.7$ & $10.9 \pm 0.3$ & $10.1 \pm 1.2$ & $9.0 \pm 0.7$ & $5.3 \pm 0.7$ \\
$\mathrm{Cd}$ & $3.3 \pm 0.4$ & $0.7 \pm 0.2$ & $0.5 \pm 0.1$ & $0.6 \pm 0.2$ & $0.6 \pm 0.2$ \\
$\mathrm{Co}$ & $1.5 \pm 1.5$ & $0.4 \pm 0.3$ & $0.2 \pm 0.1$ & $0.5 \pm 0.2$ & $0.3 \pm 0.2$ \\
$\mathrm{Cr}$ & $3.9 \pm 0.2$ & $4.5 \pm 0.7$ & $3.2 \pm 1.1$ & $2.0 \pm 0.4$ & $1.6 \pm 0.7$ \\
$\mathrm{Cu}$ & $39.0 \pm 3.1$ & $37.4 \pm 2.5$ & $22.4 \pm 3.5$ & $20.1 \pm 2.7$ & $13.3 \pm 1.4$ \\
$\mathrm{~Pb}$ & $0.6 \pm 0.2$ & $1.1 \pm 0.7$ & $1.2 \pm 0.9$ & $2.4 \pm 0.6$ & $1.2 \pm 1.7$ \\
$\mathrm{Ni}$ & $44.8 \pm 4.8$ & $12.3 \pm 2.8$ & $9.8 \pm 2.3$ & $9.1 \pm 3.3$ & $6.6 \pm 0.6$ \\
$\mathrm{Zn}$ & $129 \pm 10$ & $33 \pm 6$ & $29 \pm 9$ & $27 \pm 7$ & $38 \pm 10$ \\
\hline & & \multicolumn{5}{c}{ Sediment LG } \\
$\mathrm{As}$ & $3.9 \pm 0.5$ & $3.3 \pm 0.4$ & $3.6 \pm 0.5$ & $3.3 \pm 0.4$ & $3.0 \pm 0.0$ \\
$\mathrm{Cd}$ & $0.5 \pm 0.3$ & $0.1 \pm 0.1$ & $0.1 \pm 0.0$ & $0.2 \pm 0.2$ & $0.2 \pm 0.1$ \\
$\mathrm{Co}$ & $0.2 \pm 0.1$ & $0.3 \pm 0.2$ & $0.6 \pm 0.4$ & $0.2 \pm 0.0$ & $0.3 \pm 0.1$ \\
$\mathrm{Cr}$ & $2.6 \pm 1.4$ & $2.0 \pm 0.1$ & $2.1 \pm 0.2$ & $0.9 \pm 1.0$ & $1.0 \pm 0.2$ \\
$\mathrm{Cu}$ & $9.0 \pm 0.4$ & $5.2 \pm 1.3$ & $4.3 \pm 1.5$ & $2.5 \pm 0.0$ & $3.5 \pm 0.2$ \\
$\mathrm{~Pb}$ & $0.7 \pm 0.1$ & $0.2 \pm 0.1$ & $0.4 \pm 0.3$ & $0.2 \pm 0.1$ & $0.2 \pm 0.1$ \\
$\mathrm{Ni}$ & $3.6 \pm 1.3$ & $2.5 \pm 0.1$ & $2.5 \pm 0.1$ & $2.0 \pm 0.1$ & $2.1 \pm 0.5$ \\
$\mathrm{Zn}$ & $49 \pm 3$ & $13 \pm 2$ & $13 \pm 1$ & $12 \pm 3$ & $15 . \pm 3$ \\
\hline & & & &
\end{tabular}

*. Mean \pm standard deviation of three replicate analyses 


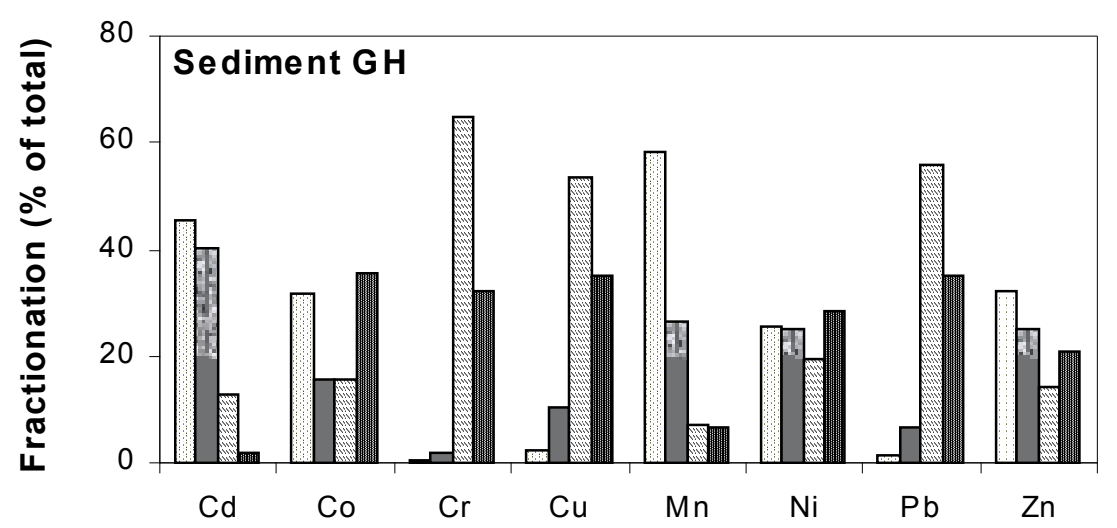

Trace Metals
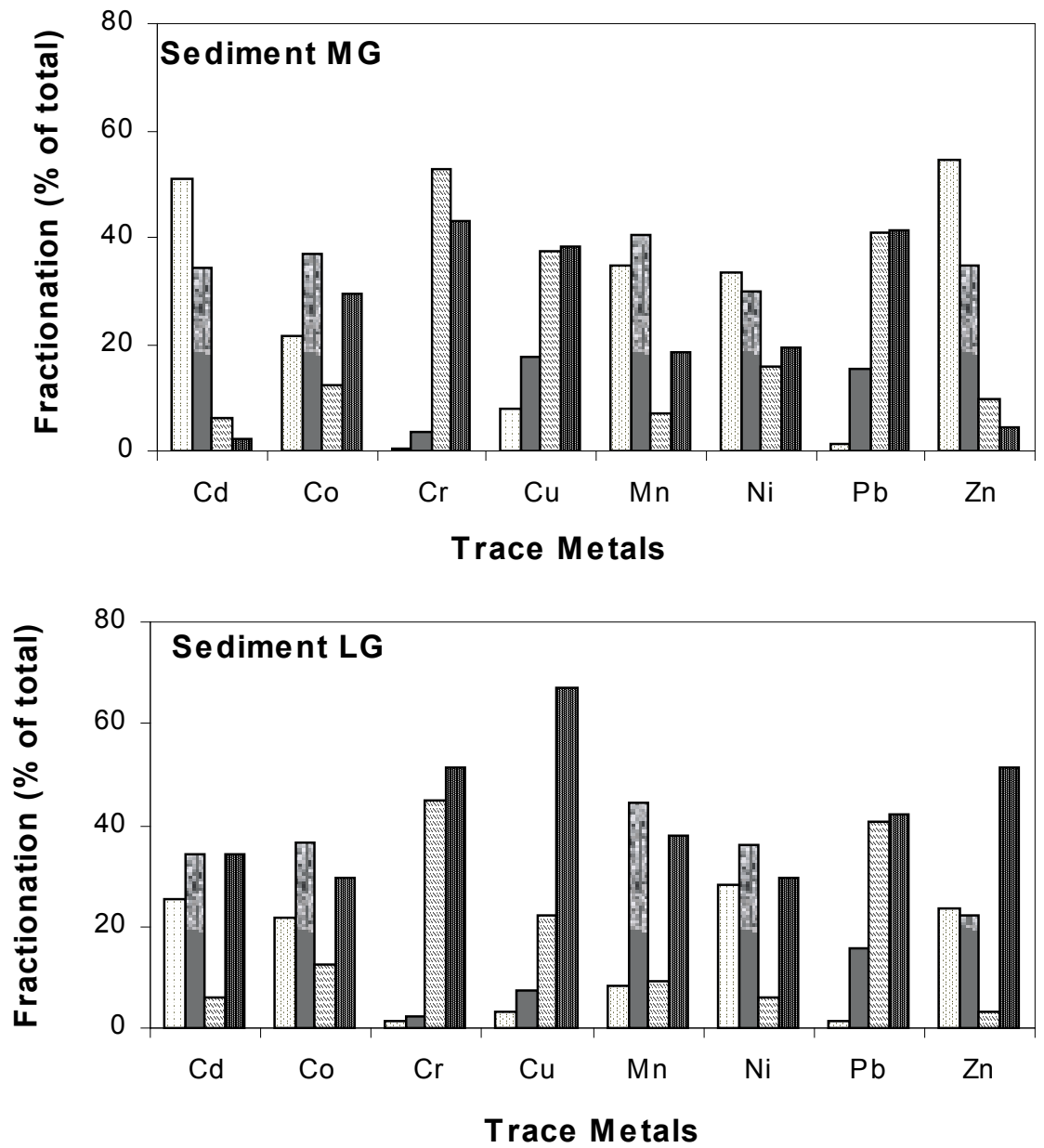

$\square$ Acid Extractable $\square$ Reducible $\square$ Oxidizable $\mathbf{m}$ Residual 

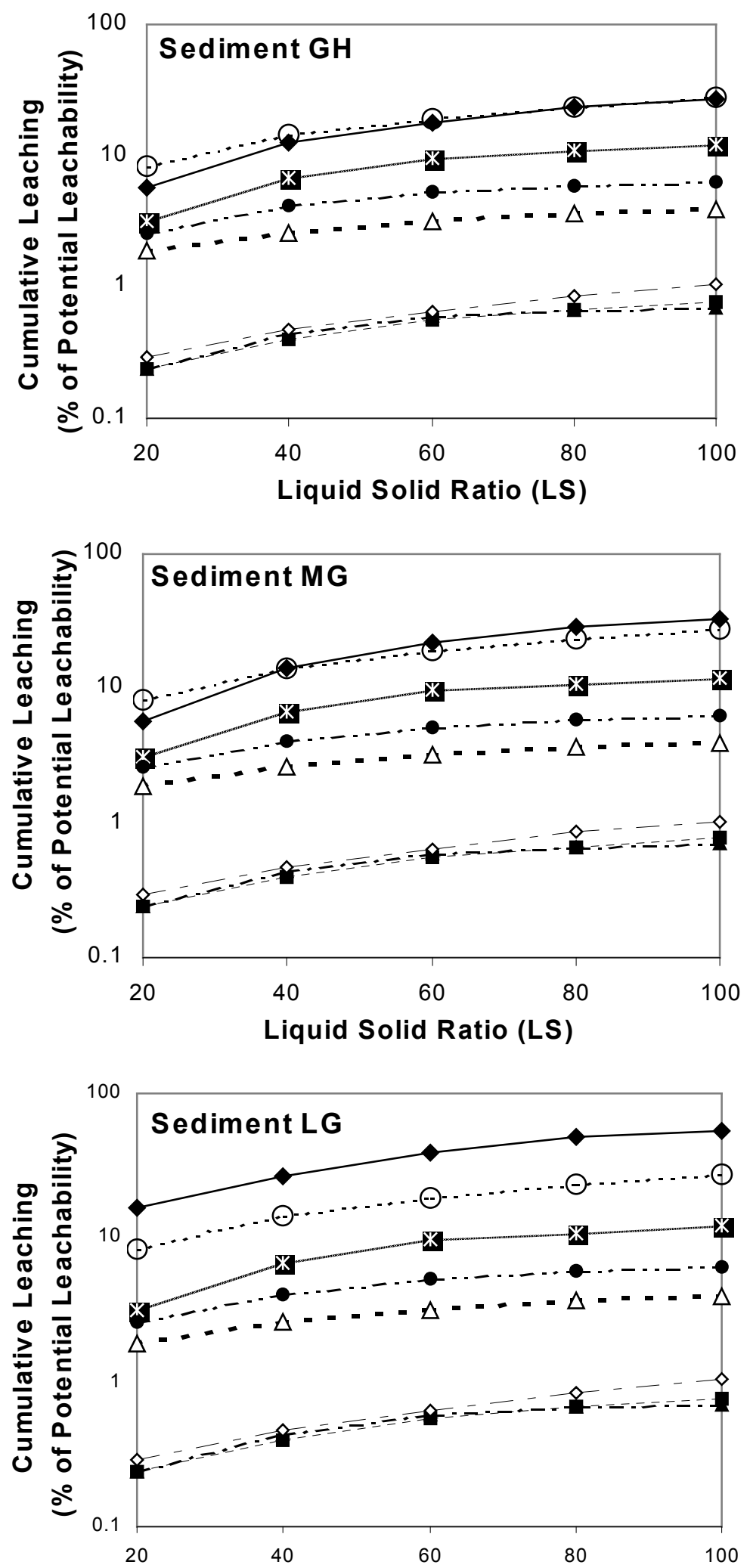

Liquid Solid Ratio (LS)

$\longrightarrow \mathrm{As}-\mathrm{C}-\mathrm{Cd}-\mathrm{-}-\mathrm{Co} \rightarrow \mathrm{X}-\mathrm{Cr}$
$\cdots \odot-\mathrm{Cu}-\cdot-\mathrm{Ni}-\cdot-\mathrm{Pb}-\diamond-\mathrm{Zn}$ 